\title{
Utilização de alfaxalona associado com meperidina e midazolam em gato obstruído*
}

\section{Use of alphaxalone associated with meperidine and midazolam in an obstructed cat}

\author{
Isabelle de Oliveira Lima, ${ }^{* *}$ Thamires Barreto Silva Souza, ${ }^{* *}$ lanne Roberta dos Santos Cardoso, ${ }^{* *}$ \\ Maria Gláucia Carlos de Oliveira, ${ }^{* *}$ Amara Gyane Alves de Lima, ${ }^{* *}$ Talyta Lins Nunes, ${ }^{* *}$ Valéria Veras de Paula**
}

\begin{abstract}
Resumo
Objetivou-se com esse trabalho avaliar o uso do anestésico alfaxalona associado à meperidina e midazolam para o procedimento de desobstrução uretral em um gato com doença do trato urinário inferior felino (DTUIF), analisando as qualidades de indução e recuperação, assim como as alterações fisiológicas. Um felino macho, quatro anos de idade, $3.1 \mathrm{Kg}$, castrado, foi atendido no setor de emergência do Hospital Veterinário da Universidade Federal Rural do Semi-árido com histórico de estrangúria, abdome distendido e vesícula urinária repleta, sendo diagnosticado com DTUIF obstrutiva. Para o procedimento de desobstrução uretral a MPA foi instituída com meperidina $3 \mathrm{mg} / \mathrm{Kg}$ por via intramuscular (IM), dez minutos após, procedeu-se a indução anestésica: $0,4 \mathrm{mg} /$ $\mathrm{Kg}$ de midazolam seguido de $2 \mathrm{mg} / \mathrm{Kg}$ de alfaxalona, ambos diluídos em água de injeção, dispostos separadamente em seringas individuais, e administrados pela via intravenosa (IV). A alfaxalona foi administrado lentamente, contabilizando 1 minuto para total fornecimento. Foram avaliadas a frequência cardíaca $(F C)$, frequência respiratória $(f)$, temperatura retal (TR), pressão arterial sistólica (PAS), média (PAM), diastólica (PAD) e hemogasometria venosa, antes, durante e após o procedimento anestésico. A alfaxalona em associação com o midazolam produziu perda rápida da consciência, do reflexo de deglutição e intenso relaxamento muscular, bem como boa qualidade de indução e recuperação. O protocolo utilizado produziu mínimas anormalidades clinico patológicas, sem alterações importantes nos parâmetros cardíacos e respiratórios durante todo o procedimento, com manutenção da pressão arterial. Portanto, o anestésico alfaxalona foi considerado seguro para o procedimento de desobstrução uretral em gato macho com DTUIF.
\end{abstract}

Palavras chaves: analgesia, felino, hemogasometria venosa, DTUIF

\section{Abstract}

The aim of this study was to evaluate the use of the anesthetic alfaxalone in combination with meperidine and midazolam as an anesthetic protocol for managing urethral obstruction in a male cat with feline lower urinary tract disease (FLUTD), and verify the quality of the induction and recovery as well as the physiological changes. A male four-year-old cat, weighing $3.1 \mathrm{~kg}$, was admitted to the emergency service of the Veterinary Hospital at the Federal Rural Semi-Arid University, with a clinical history of stranguria, haematuria, distended abdomen and an enlarged urinary bladder. To prepare to unblock the urethral obstruction, intravenous (IV) Lactated Ringer's solution (RL) administration was initially performed. The anesthetic protocol used was $3 \mathrm{mg}^{\mathrm{kg}} \mathrm{kg}^{-1}$ meperidine IM, followed by $0.4 \mathrm{mg} \cdot \mathrm{kg}^{-1}$ midazolam IV given immediately before $2 \mathrm{mg} \cdot \mathrm{kg}^{-1}$ alfaxalone IV. Heart rate (HR), respiratory rate (RR), rectal temperature (RT), systolic arterial pressure (SAP), mean arterial pressure (MAP), diastolic arterial pressure (DAP) and venous blood gases were evaluated before, during and after the anesthesia. There was no significant variation in the analyzed parameters after administration of meperidine. Alfaxalone, in combination with midazolam, produced rapid loss of consciousness, swallowing reflex and intense muscle relaxation, as well as a good quality of induction and recovery. The presented protocol induced minimal clinical pathological abnormalities, no significant changes in cardiac and respiratory parameters throughout the procedure, with maintenance of the blood pressure. Therefore, the anesthetic alfaxalone was considered safe for managing urethral obstruction in male cat with FLUTD.

Keywords: analgesia, feline, venous blood gases, FLUTD

\footnotetext{
*Recebido em 17 de fevereiro de 2017 e aceito em 24 de fevereiro de 2018

**Universidade Federal Rural do Semi-Árido.

Autor para correspondência: lima-io@bol.com.br
} 


\section{Introdução}

A obstrução urinária é uma afecção comum envolvendo o trato urinário inferior felino (RIESER, 2005). Ela é caracterizada como uma emergência, e se não tratada rapidamente pode resultar em alterações clínicas importantes, tais como azotemia, acidose metabólica, hipercalemia, hiperfosfatemia e hipocalcemia (LEE, 2003).

O quadro torna-se crítico se a obstrução uretral se estender por mais de 36 horas ou se houver uma diminuição da ingestão de água por mais de 24 horas (SOARES et al., 2005; REINEKE, 2014). A desobstrução uretral é um procedimento doloroso, com isso os gatos devem ser adequadamente sedados ou submetidos à anestesia geral para maximizar o relaxamento uretral, diminuindo o risco de trauma e eliminando a dor no momento da passagem da sonda uretral (REINEKE, 2014). Contudo, a escolha dos agentes anestésicos e sedativos dependerá do estado clínico e dos achados laboratoriais do paciente (JERICÓ, 2015).

Devido às alterações eletrolíticas e cardiovasculares presentes nesses animais, há dificuldade em se encontrar fármacos seguros para esse tipo de procedimento, o que torna importante o reconhecimento preciso do estado clínico do paciente para a escolha do protocolo mais apropriado (JERICÓ, 2015).

A alfaxalona (2-hidroxypropyl- $\beta$-cyclodextrin, HPBC) é um esteroide neuroativo sintético que, assim como o propofol, atua no receptor inibitório ácido gama amino butírico (GABA). Este por sua vez, aumenta a interação do neurotransmissor inibitório GABA tipo A, um complexo receptor que produz anestesia e relaxamento muscular. O seu mecanismo de ação se dá pelo movimento de $\mathrm{Cl}^{-}$para dentro da célula, inibindo assim a propagação do seu potencial de ação (HARRISON e SIMMONDS, 1984; ALBERTSON, 1992; LAMBERT et al., 2003; WARNE et al., 2015).

A alfaxalona em doses clínicas tem sido associado à indução e recuperação suaves com menor efeito depressor na função cardiorrespiratória e mínimos efeitos acumulativos em gatos, podendo ser uma boa opção em substituição ao propofol em anestesia. Com estas características benéficas, alfaxalona tem sido muito utilizado para indução anestésica de cães e gatos na Austrália, Nova Zelândia, África do Sul e Reino Unido (WITTEN, 2008; MUIR, 2009).

Para potencializar os efeitos anestésicos e hipnóticos da alfaxalona, os benzodiazepínicos podem ser utilizados. São fármacos que possuem efeitos ansiolíticos, tranquilizantes, hipnóticos e miorrelaxantes importantes para o procedimento de desobstrução uretral (FANTONI, 2002). O midazolam, em dose clínica $(0,1 \mathrm{mg} / \mathrm{Kg})$, tem sido relacionado a mínimos efeitos cardiovasculares, possuindo vantagens em relação ao diazepam pela meia vida curta de (1,7 hora) e com maior potência hipnótica. É um fármaco hidrossolúvel permitindo maior facilidade de administração por diferentes vias (CHAI, WANG, 1966; FANTONI, 2002).

A meperidina, opióide agonista com afinidade pelos receptores $\mu$, é um fármaco que promove boa analgesia. É utilizada em procedimentos relacionados à dor moderada com um período de ação de 1 hora e meia, tempo médio adequado para o procedimento de cateterização uretral. Entretanto, a sua administração deve ser feita pela via intramuscular, preferencialmente, pois a administração intravenosa pode causar grande liberação de histamina e hipotensão (LASCELES, 1999; GÓRNIAK, 1996).

Diante dos aspectos abordados, o objetivo desse trabalho foi avaliar o uso do anestésico alfaxalona associado à meperidina e ao midazolam para o procedimento de desobstrução urinária em um gato com doença do trato urinário inferior felino (DTUIF) através das qualidades de indução e recuperação, e também das alterações fisiológicas.

\section{Relato do caso}

Um felino macho, quatro anos de idade, pesando $3,1 \mathrm{Kg}$, castrado, com histórico de estrangúria, foi atendido no setor de emergência clínica do Hospital Veterinário "Dix-huit Rosado Maia" da Universidade Federal Rural do Semi-Árido. O animal é domiciliado e a alimentação é baseada em ração seca comercial. De acordo com a anamnese, o paciente não tinha histórico anterior de doença urinária, sendo relatado anorexia e oligodipsia. Ao exame físico inicial, o animal encontrava-se em decúbito esternal, apático, com aproximadamente $7 \%$ de desidratação, bom estado nutricional, hipotérmico (temperatura retal $37.2^{\circ} \mathrm{C}$ ), frequência cardíaca de 120 batimentos por minuto (bpm), eupneico e com campos pulmonares limpos à auscultação. Apresentava distensão abdominal e vesícula urinária repleta e rígida à palpação. Foram coletados $3 \mathrm{~mL}$ de sangue para a realização do hemograma e bioquímica séricas, os quais revelaram um quadro de leucocitose $\left(63400 / \mathrm{mm}^{3}\right)$ e valores aumentados de uréia e creatinina $225 \mathrm{mg} / \mathrm{dL}$ e $7 \mathrm{mg} /$ $\mathrm{dL}$, respectivamente (EISENBERG et al., 2013). A partir de então, foi firmado o diagnóstico de doença do trato urinário inferior felino (DTUIF) obstrutiva. O tratamento consistiu na desobstrução urinária.

O paciente foi cateterizado na veia cefálica para administração de solução de Ringer com lactato, a uma taxa de $6 \mathrm{ml} / \mathrm{kg} / \mathrm{h}$ (REINEKE et al., 2014) e posicionado sob um colchão térmico para recuperação da temperatura corporal. Para a desobstrução urinária é necessário procedimento anestésico, a avaliação pré-anestésica compreendeu aferição das seguintes variáveis: coloração das mucosas ocular e oral; tempo de preenchimento capilar (TPC), obtido por meio da compressão digital na mucosa gengival durante 3 segundos; qualidade do pulso (palpação da artéria femoral); frequência cardíaca (FC), mensurada por auscultação dos batimentos cardíacos durante um minuto com auxílio de um estetoscópio posicionado na altura do coração no lado esquerdo da região torácica; frequência respiratória (f), através da inspeção direta dos movimentos respiratórios do animal em repouso durante 1 minuto; temperatura retal (TR), que foi obtida com o auxílio de um termômetro clínico digital, em graus Celsius; pressão arterial sistólica (PAS), pressão arterial média (PAM) e pressão arterial diastólica (PAD), utilizando o dispositivo (PetMap) de avaliação da pressão oscilométrica, acoplado no membro torácico com o manguito de tamanho apropriado posicionado acima da região do carpo; hemogasometria, a partir da análise de amostra de sangue venoso $(0,1 \mathrm{~mL})$, por meio do aparelho de hemogasometria portátil I- Stat, com seringa heparinizada com a imediata vedação da agulha. Foi utilizado cartucho CG8+ que fornece os dados de potencial hidrogeniônico $(\mathrm{pH})$, pressão parcial de dióxido de carbono $\left(\mathrm{pCO}_{2}\right)$, pressão parcial de oxigênio $\left(\mathrm{pO}_{2}\right)$, dióxido de 
carbono total $\left(\mathrm{TCO}_{2}\right)$, bicarbonato $\left(\mathrm{HCO}_{3}\right)$, excesso de base $(\mathrm{BE})$, glicose, sódio, potássio, hematócrito e hemoglobina.

Para melhor controle do quadro do animal durante o procedimento de desobstrução, foram determinados momentos de avaliação das variáveis fisiológicas e hemogasométricas, sendo: momento pré-anestésico (M0); 5 minutos após indução anestésica (M1); 10 minutos após M1 (M2), e a cada 10 minutos consequentes; e 1h após indução anestésica (M1h)

A medicação pré-anestésica (MPA) consistiu em $3 \mathrm{mg} / \mathrm{Kg}$ de meperidina pela via intramuscular (IM). Dez minutos após, procedeu-se a indução anestésica: $0,4 \mathrm{mg} / \mathrm{Kg}$ de midazolam seguido de $2 \mathrm{mg} / \mathrm{Kg}$ de alfaxalona, ambos diluídos em água de injeção, dispostos separadamente em seringas individuais, e administrados pela via intravenosa (IV). A alfaxalona foi administrado lentamente, contabilizando 1 minuto para total fornecimento.

A indução foi avaliada 1 minuto após a aplicação do anestésico alfaxalona, tempo equivalente ao término do seu período de latência (MADDISON et al., 2010). Esse quesito foi avaliado conforme o grau de relaxamento muscular, de maneira subjetiva, observando a resistência à abertura da boca e flexão do membro pélvico (CASTRO, 2010; COVEY-CLUMP; MURISON, 2008), obedecendo aos seguintes critérios: 1 = intenso relaxamento muscular (ausência de resistência à abertura bucal e flexão do membro); 2 = discreto relaxamento muscular (moderada resistência à abertura bucal e/ou flexão do membro); 3 = tônus do membro e mandíbula normais.

Após apresentar os parâmetros adequados para indução, onde foi avaliado em escore um, deu-se início ao procedimento de desobstrução uretral. A sonda utilizada para o processo de desobstrução foi a TOM CAT ${ }^{\circledR}$, medindo $1.3 \mathrm{~mm}$ de espessura $\mathrm{x}$ $130 \mathrm{~mm}$ de comprimento para a cateterização do lúmen uretral do animal. O tempo gasto desde o processo de início da passagem da sonda até a desobstrução total da uretra foram 40 minutos.

A recuperação foi avaliada de forma quantitativa, sendo contabilizado o tempo desde a indução da anestesia até o momento em que o animal levantou a cabeça pela primeira vez, contabilizando 45 minutos. A recuperação também foi avaliada de forma qualitativa, conforme o protocolo estabelecido por Muir et al. (2009), adotando o tempo em que o animal posiciona-se em decúbito esternal e levanta a cabeça pela primeira vez. Desta maneira, foram atribuídos os seguintes escores durante a recuperação anestésica: 1 = assumir decúbito esternal com pouco ou nenhum esforço, apresentando pouca ou nenhuma dificuldade de ficar em estação; 2 = o animal apresenta dificuldades de ficar em decúbito esternal ou em estação, requerendo auxílio, apresentando sensibilidade aos estímulos externos, animal tranquilo em decúbito esternal; 3 = animal relutante, e com dificuldade em manter-se em decúbito esternal ou ficar em estação, apresentando hipercinesia e movimentos prolongados de pedalagem. $\mathrm{O}$ felino do presente relato apresentou escore 2.

Após o procedimento desobstrução uretral, foi administrado $0,1 \mathrm{mg} / \mathrm{Kg}$ de meloxicam, $25 \mathrm{mg} / \mathrm{Kg}$ de dipirona, ambos pela via $\mathrm{IV}$, e cloridrato de tramadol $3 \mathrm{mg} / \mathrm{kg}$, por via IM.

\section{Discussão}

A DTUIF obstrutiva é uma enfermidade comum na medicina de felinos. O animal do presente relato apresentou alguns fatores associados ao risco da doença: confinamento e alimentação exclusiva de ração seca (LITTLE, 2016).

O quadro clínico do paciente tornou-se crítico dado o período superior às $24 \mathrm{~h}$ de obstrução urinária, acompanhado de anorexia e oligodipsia. Nessas situações, a questão potencialmente fatal não é a obstrução em si, mas sim, o comprometimento cardiovascular resultante da hipercalemia que se instala, gerando arritmias cardíacas (SOARES et al., 2005; REINEKE, 2014; LITTLE, S. E, 2016).

Ao exame físico inicial, o animal apresentava mucosas normocoradas, porém o TPC aumentado (3 segundos), pulso normocinético, bulhas cardíacas regulares e normofonéticas à auscultação, com FC de 120 bpm, considerado dentro da variação normal para espécie segundo Feitosa (2008), porém esse valor, no limite inferior da referência pode estar associado ao quadro de hiperpotassemia já instalado, pois a concentração sérica de potássio durante a avaliação pré-anestésica foi de 7 $\mathrm{mmol} / \mathrm{L}$ (LITTLE, 2016).

Durante avaliação pré-anestésica, as variáveis mensuradas apresentaram os seguintes resultados: FC 152 bpm, f24mpm, TR 37,2 ${ }^{\circ} \mathrm{C}$, PAS $160 \mathrm{mmHg}$, PAM 135mmHg, PAD $120 \mathrm{mmHg}$. Após a medicação pré-anestésica com meperidina, na dose de $3 \mathrm{mg} / \mathrm{Kg}$, a FC baixou para $140 \mathrm{bpm}$, a $f$ permaneceu em $24 \mathrm{mpm}$, a TR foi de $37,8^{\circ} \mathrm{C}$ e as PAS, PAM e PAD de 155, 135 e $120 \mathrm{mmHg}$, respectivamente, demonstrando que, na dose supracitada, esse opioide não alterou os parâmetros fisiológicos de forma significativa. Uma das grandes vantagens do emprego da meperidina é sua relativa ausência de efeitos adversos, proporcionando mínima depressão no sistema cardiovascular (FANTONI, 2002). Segundo Reisine e Pasternak (2001), a administração de meperidina pode proporcionar depressão respiratória, porém não foi observado nesse estudo.

A FC basal foi considerada elevada em comparação com a FC obtida em gatos em ambiente domiciliar (ABBOTT, 2005), o que também foi observado nos valores de pressão arterial (SLINGERLAND et. al, 2008). De acordo com Anjos (2013), isso pode ocorrer devido a liberação de catecolaminas causado pela ansiedade e estresse à manipulação. Após indução anestésica com alfaxalona, a FC aumentou para 200bpm, e manteve essa média durante e após o procedimento de desobstrução uretral. Esses dados diferem dos encontrados por Muir et. al (2009), em que a FC diminuiu após a administração de alfaxalona em gatos hígidos, utilizando as dose de 5,15 e $50 \mathrm{mg} / \mathrm{Kg}$, sendo esses efeitos doses dependentes e mais pronunciados com a dose mais alta $(50 \mathrm{mg} / \mathrm{Kg})$, contudo os autores utilizaram como estímulo nocivo o pinçamento interdigital, que é um estímulo mecânico para dor somática, podendo desencadear algia menor que a produzida pela desobstrução uretral. Em nenhum momento foi observado hipotensão (PAM abaixo de $70 \mathrm{mmHg}$ ) (ANJOS, 2013). Muir et. al (2009), afirmaram que doses de 2 a $5 \mathrm{mg} / \mathrm{Kg}$ de alfaxalona promovem insignificantes alterações na resistência vascular sistêmica e no débito cardíaco, em felinos.

O animal não apresentou apneia ou desconforto respiratório durante o procedimento. A $f$, após a administração da alfaxalona, manteve-se dentro dos limites normais para a espécie, com média de $23 \mathrm{mpm}$, variando de 20 a 38mpm (FEITOSA, 2008). Houve um aumento na $f$ para $38 \mathrm{mpm}, 45$ minutos após a indução, durante o procedimento de desobstrução, o que difere de Muir et al. (2009), no qual a $f$ e o volume minuto diminuíram após a administração do anestésico alfaxalona IV 
em gatos hígidos nas dose de 5,15 e $50 \mathrm{mg} / \mathrm{Kg}$. É possível que o aumento da frequência respiratória tenha sido em parte devido a resposta compensatória ao quadro clínico da acidose metabólica (RIESER, 2013).

A TR manteve- se dentro dos limites fisiológicos, com média de $37.8^{\circ} \mathrm{C}$ variando entre 37.2 a $38.1^{\circ} \mathrm{C}$, valor médio também encontrado por Lee et. al. (2003).

$\mathrm{Na}$ hemogasometria venosa foram encontrados os seguintes valores (Tabela 01):

Tabela 1: Variáveis hemogasométricas venosa de felino com DTUIF anestesiado com alfaxalona para procedimento de desobstrução urinária

\begin{tabular}{cccccc}
\hline $\begin{array}{c}\text { Momentos/ } \\
\text { Variáveis }\end{array}$ & $\mathrm{pH}$ & $\begin{array}{c}\mathrm{pCO} 2 \\
(\mathrm{mmHg})\end{array}$ & $\begin{array}{c}\mathrm{pO}_{2} \\
(\mathrm{mmHg})\end{array}$ & $\begin{array}{c}\mathrm{HCO}_{3} \\
(\mathrm{mmol} / \mathrm{L})\end{array}$ & $\begin{array}{c}\mathrm{BE} \\
(\mathrm{mmol} / \mathrm{L})\end{array}$ \\
\hline M0 & 7,256 & 33,9 & 44 & 15,1 & -12 \\
M1 & 7,169 & 42,6 & 50 & 15,3 & -13 \\
M1h & 7,236 & 34,8 & 41 & 14,6 & -13
\end{tabular}

M0: momento pré-anestésico; M1: 5 minutos após indução; M1h: 1h após recuperação; ph: potencial hidrogeniônico; $\mathrm{pCO}_{2}$ : pressão parcial de dióxido de carbono; $\mathrm{pO}_{2}$ : pressão parcial de oxigênio; $\mathrm{TCO}_{2}$ : concentração total de dióxido de carbono; $\mathrm{HCO}_{3}$ : bicarbonato; $\mathrm{BE}$ : excesso de base. $\mathrm{O}$ intervalo de referência para as variáveis de interesse em gatos: $\mathrm{pH} 7,3-7,4 ; \mathrm{pCO}$ 33-43 mmHg; $\mathrm{pO}_{2} 41-51 \mathrm{mmHg} ; \mathrm{HCO}_{3}$ 17,3-24, $1 \mathrm{mmol} / \mathrm{L} ; \mathrm{BE}-1$ a $-7 \mathrm{mmol} / \mathrm{L}$.

Analisando os valores de $\mathrm{pH}, \mathrm{pCO}_{2}$ e $\mathrm{HCO}_{3}$, observou-se quadro de acidose metabólica antes, durante e após a anestesia, já que o pH sanguíneo apresentou-se abaixo dos valores fisiológicos de referências para espécie, sendo acompanhado de diminuição nos valores do $\mathrm{HCO}_{3}$ (LEE et al., 2003; EISENBERG et al., 2013). Valores semelhantes foram encontrados por Lee et al. (2003), que obteve uma média de $\mathrm{pH}$ sanguíneo de 7,29 . A acidose metabólica intensa $(\mathrm{pH}<7,1)$ provoca alterações nos sistemas respiratório, cardiovascular e do sistema nervoso central (LEE, 2006).

O gato atendido apresentou hipercalemia, pois este se encontrava acima dos valores de referência $(3,4-4,6$ mmol/L) (EISENBERG et al., 2013). (Tabela 02). A hipercalemia é considerada a complicação mais comum nessa condição, com risco de morte (LEE, 2006), já que reduz o potencial de repouso das membranas celulares do miocárdio, produzindo efeito de bloqueio despolarizante e diminui a condução elétrica. Como resultado, causa fraqueza muscular e alteração da propagação de impulso elétrico das células cardíacas (SCHAEFER, 2005).

Freitas et al. (2011) apresentaram essa mesma situação: acidose metabólica e hipercalemia em gatos obstruídos e tratados com propofol e cetamina/diazepam, permanecendo o desequilíbrio por até 2 horas após o alívio uretral.

Devido à obstrução uretral, a bexiga dilata-se além da sua capacidade normal, levando ao aumento da pressão intravesical e a urina retida ascende novamente aos rins. Essa situação promove aumento da pressão intrabular, opondo forças contra a taxa de filtração glomerular, comprometendo a capacidade de concentração tubular, além de outras funções tubulares, entre elas, a regulação do sódio e a capacidade de reabsorção de água, ainda, prejudicando a excreção de ácidos e potássio, resultando em uremia, acidose e hipercalemia (LANE, 2009).

Gatos com acidose metabólica raramente precisam ser tratados por meio de bicarbonato, pois os rins conseguem corrigir o desequilíbrio acido básico após reidratação e o tratamento da doença primária, medida adotada no neste relato. $\mathrm{O}$ tratamento só deve ser realizado quando, apesar de fluidoterapia por um período de 12 a $24 \mathrm{~h}$, a acidose metabólica permanecer grave $(\mathrm{pH}$ inferior a 7,1) ou o bicarbonato for menor que $12 \mathrm{mEq} / \mathrm{l}$ (LUNN et al. 2016), devendo-se fazer uso das soluções eletrolíticas balanceadas, que apesar de conterem pequenas concentrações de potássio, auxiliam na correção da acidose metabólica (LAPPIN \& BLANCO, 2004).

Para estabilizar clinicamente o paciente, optou-se pela fluidoterapia com solução de Ringer com lactato, 15 minutos antes da desobstrução e permanecendo após o alívio uretral. A maioria dos pacientes tratados com soluções de substituição contendo lactato responde bem ao tratamento da acidose metabólica, provavelmente devido a expansão do volume extracelular e melhora da perfusão tecidual (DIBARTOLA, 2012).

Durante todo o procedimento, não houve alterações clínicas significativas nos valores hematológicos de hematócrito e hemoglobina, glicose e sódio (LEE et al. 2003) (Tabela 02). Também não foram associadas alterações na hematologia ou na bioquímica sanguínea em anestesia com alfaxalona em gatos por Whittem et al. (2008).

Os dados do hematócrito diferem de Freitas et al. (2011), que observaram significativa diminuição do hematócrito em gatos obstruídos e anestesiados com propofol e associação de cetamina e diazepam. Isso provavelmente foi causado pela hematúria, como resultado da ruptura dos vasos após a hiperdistensão vesical bem como pela hemodiluição causada pela fluidoterapia e pelo volume acumulado de sangue coletado para avaliação (FREITAS et al. 2011; LUNN et al. 2016).

Tabela 2: Valores de hematócrito, hemoglobina, glicose, sódio e potássio de felino com DTUIF anestesiado com alfaxalona para procedimento de desobstrução urinária

\begin{tabular}{cccccc}
\hline $\begin{array}{c}\text { Momentos/ } \\
\text { Variáveis }\end{array}$ & $\begin{array}{c}\text { Hematócrito } \\
(\%)\end{array}$ & $\begin{array}{c}\text { Hemoglobina } \\
(\mathrm{g} / \mathrm{L})\end{array}$ & $\begin{array}{c}\text { Glicose } \\
(\mathrm{mg} / \mathrm{dL})\end{array}$ & $\begin{array}{c}\text { Sódio } \\
(\mathrm{mmol} / \mathrm{L})\end{array}$ & $\begin{array}{c}\text { Potássio } \\
(\mathrm{mmol} / \mathrm{L})\end{array}$ \\
\hline M0 & $39 \%$ & 13,3 & 129 & 141 & 7 \\
M1 & $34 \%$ & 11,6 & 123 & 141 & 6,2 \\
M1h & $36 \%$ & 12,2 & 106 & 143 & 5,3 \\
\hline
\end{tabular}

M0: momento pré-anestésico; M1: 5 minutos após indução; M1h: 1h após recuperação. O intervalo de referência para as variáveis de interesse em gatos: Hematócrito: $32-48$ $\%$ Hemoglobina 8-15 g/L ; Glicose 67-168 mg/dL; Sódio 147-157 mmol/L; Potássio 3,4- 4,6 $\mathrm{mmol} / \mathrm{L}$.

As doses utilizadas do protocolo anestésico permitiram a realização da desobstrução, não sendo necessário bollus adicional. Freitas et al. (2011), ao utilizarem propofol na dose de $5 \mathrm{mg} / \mathrm{Kg}$ para o mesmo procedimento, necessitaram de uma dose adicional, provavelmente devido ao curto período de 
ação do fármaco. Não foi observado nenhum efeito colateral da alfaxalona, como apnéia. Este fato pode ser justificado pela utilização de uma dose baixa de alfaxalona nesse relato $(2 \mathrm{mg} /$ $\mathrm{Kg}$ ), pois Muir et al. (2009) observaram esse efeito em dose maiores de 15 e $50 \mathrm{mg} / \mathrm{Kg}$ de alfaxalona em gatos hígidos.

Quanto a qualidade da indução, o animal apresentou intenso relaxamento muscular com ausência de resistência a abertura bucal e flexão do membro. A qualidade de indução com a alfaxalona também foi observada por Muir et al. (2009) em gatos hígidos, no qual considerou a indução de boa a excelente, observando decúbito suave e completo relaxamento muscular com mínima ou nenhuma resposta aos estímulos nocivos.

No que diz respeito a recuperação, foi atribuído escore 2 ao animal do presente relato, uma vez que foi observado dificuldade para ficar em decúbito esternal, requerendo auxílio, apresentando-se tranquilo em decúbito esternal. Estes dados diferem de Muir et al. (2009) em gatos hígidos, com as doses de 5 e $15 \mathrm{mg} / \mathrm{kg}$, que utilizando a mesma tabela de avaliação atribuiu o escore 1 .

O tempo para levantar a cabeça pela primeira vez foi contado a partir do momento em que foi administrada alfaxalona, sendo registrado 45 minutos, tempo menor quando comparado com gatos anestesiados com cetamina $(10 \mathrm{mg} / \mathrm{kg}$ ) e diazepam $(5 \mathrm{mg} /$ $\mathrm{Kg}$ ), que apresentaram um tempo de recuperação de 75 minutos. (FREITAS, et al., 2011).

\section{Referências}

ABBOTT, J. A. Heart rate and heart rate variability of healthy cats in home and hospital environments. Journal of Feline Medicine and Surgery, v. 7, n. 3, p. 195-202, 2005. Disponível em: https:// www.ncbi.nlm.nih.gov/pubmed/?term=heart+rate+and+heart+rate +variability+oh+healthy+cats+in+home+and+hospital+environmen ts. Acesso em 13 dez. 2016.

ALBERTSON, T.E. Modification of GABA-mediated inhibition by various injectable anesthetics. Anesthesiology, v. 77, n. 3, p. 488, 1992. Disponível em: https://www.ncbi.nlm.nih.gov/pubmed/?term =Modification+of+GABA-mediated+inhibition+by+various+injectab le+anesthetics. Acesso em 08 dez. 2016.

ANJOS, M. T. Avaliação e comparação entre métodos de mensuração de pressão arterial sistólica em gatos hígidos. 2013. 106 f. Dissertação (Mestrado em Ciência Animal)- Escola de Veterinária- Universidade Federal de Minas Gerais, 2013. Disponível em: http://www.scielo.br/scielo.php?script=sci_arttext\& pid=S0102-09352014000401051. Acesso em 01 dez. 2016.

CASTRO, D. G. Efeitos do midazolam, associado ao propofol, na indução da anestesia em gatas submetidas a ovariossalpingohisterectomia. 2010. 111 f. Dissertação (Mestrado em Ciênciais) - Faculdade de Medicina Veterinária e Zootecnia- Universidade de São Paulo, São Paulo, 2010. Disponível em: http://www.teses. usp.br/teses/disponiveis/10/10137/tde-27012012-093140/pt-br. php. Acesso em 05 fev. 2016.

COVEY-CRUMP, G. L; MURISON, P. J. Fentanyl or midazolam for co-induction for anesthesia with propofol in dogs. Veterinary Anesthesia and Analgesia, v 35, n. 6, p. 463-472, 2008.

CHAI CY, WANG SC. Cardiovascular actions of diazepam in cats. Journal of Pharmacology Experimental Therapeutics, v. 154, p. 271- 280, 1966.
A alfaxalona tem uma curta duração de ação quando usado como agente de indução em gatos. Muir e et al., (2009) relataram um tempo médio de 26,0 $(10,7)$ minutos desde a intubação até a extubação após $5 \mathrm{mg} / \mathrm{kg}$ de alfaxalona. A duração da anestesia no presente estudo foi de 60 minutos (tempo em que o animal apresentou a posição quadrupedal). Nessas circunstâncias, é provável que o tempo de recuperação assim como a qualidade da recuperação tenha sido influenciado pelas alterações acidobásica e eletrolítica do animal, tanto pela acidose metabólica quanto pela hipercalemia, o que explicaria essas diferenças nos tempos.

A alfaxalona, em associação com o midazolam, produziu efeitos anestésicos típicos de anestésicos hipnóticos, com perda rápida da consciência, perda do reflexo de deglutição e intenso relaxamento muscular.

\section{Conclusão}

A anestesia com alfaxolona forneceu boa qualidade de indução e recuperação. $\mathrm{O}$ gato do presente relato esteve relativamente estável durante o procedimento, com mínimas anormalidades clínico patológicas, sem alterações importantes nos parâmetros cardíacos e respiratórios e com manutenção da pressão arterial. Portanto, o anestésico alfaxalona foi considerado seguro para o procedimento de desobstrução uretral em gato macho com DTUIF obstrutiva.

DIBARTOLA, S. P.; BATEMAN S. Introduction to fluid therapy. In: DIBARTOLA SP, ed. Fluid, Electrolyte, and Acid-base Disorders in Small Animal Practice. St. Louis: Saunders Elsevier, 2012, p. 330-350.

EISENBERG, B. W.; WALDROP, J. E.; ALLEN, A. E; BRISSON, J. O.; ALOISIO, K. M.; HORTON, N. J, Evaluation of risk factors associated with recurrent obstruction in cats treated medically for urethral obstruction. Journal of the Amaricam Veterinary Medical Association. v. 243, n. 8, p 1140 -1146, 2013. Disponível em: http://avmajournals.avma.org/doi/abs/10.2460/ javma.243.8.1140?url_ver=Z39.88-2003\&rfr_id=ori:rid:crossref. org\&rfr_dat=cr_pub\% $\overline{3}$ dpubmed. Acesso em 15 jul. 2017.

FANTONI, D. T. Fisiopatologia e controle da dor. In: FANTONI, D. T.; MASTROCINQUE, S. Anestesia em cães e gatos. São Paulo: Roca, 2002, 323-336.

FEITOSA, F. L.F. Exame físico geral ou de rotina. In: FEITOSA, F. L.F. (2ed) Semiologia Veterinária. A arte do diagnóstico. São Paulo: Roca, 2008, p. 63- 86.

FREITAS, G. C.; CUNHA, M. G. M. C. M.; GOMES, K.; CUNHA, J. P. M. C. M.; TOGNI, M; PIPPI, N. L.; CARREGARO, A. B. Acidbase and biochemical stabilization and quality of recovery in male cats with urethral obstruction and anesthetized with propofol or a combination of ketamine and diazepam. The Canadian Journal of Veterinary Research, v. 76, p. 201-208, 2011.

GÓRNIAK, S. L. Hipnoanalgésicos e neuroleptoanalgesia. In: SPINOSA, H. S.; GÓRNIAK, S. L., BERNARDI, M.M. Farmacologia aplicada à medicina veterinária . 1. ed. Rio de Janeiro: Guanabara Koogan, p.141-6, 1996.

HARRISON, N.L., SIMMONDS, M.A. Modulation of the GABA receptor complex by a steroid anaesthetic. Brain Research, v. 323, p. 287-292, 1984. 
RECHE JUNIOR, A.; CAMOZZI, R. B. Doença do TratoUrinário Inferior dos Felinos-Cistite Intersticial. In. JERICÓ, M. M., KOGIKA, M. M., NETO ANDRADE, J. P. Tratado de Medicina Interna de Cães e Gatos: 1. ed. Rio de Janeiro: Roca, 2015, p. 1483-1492.

LAMBERT, J.J.; BELELLI, D.; PEDEN, D. R.; VARDY, A. W.; PETERS, J. A Neurosteroid modulation of GABAA receptors. Progress in Neurobiology, v. 71, p. 67-80, 2003.

LANE I. Urethral obstruction in cats: Catherters and complications (Proceedings): CVC. Capturado em 01 de jun. 2009. Online. Disponível na Internet http://veterinarycalendar.dvm360.com/ avhc/Feline+medicine/Urethral-obstruction-in-cats-Catheters-andcomplic/ArticleStandard/Article/detail/608438

LAPPIN R.M. \& BLANCO J.L. Infecções do trato urinário. In: Lappin R. M. (ed.) Segredos em medicina interna de felinos. Editora Artmed, São Paulo, 2004, p. 281-28.

LASCELES, B.D.D.X. Analgesia pré-operatória- opiaceos y AINEs. Waltham Focus, v. 4, n. 9, p. 2-9, 1999.

LUNN, K. F.; JOHNSON, A. S.; JAMES, K. M. Fluidoterapia. In: LITTLE, S. E. (1.ed). O gato. Rio de Janeiro: Roca, 2016, p. 5085.

LEE JA, DROBATZ KJ. Characterization of the clinical characteristics, electrolytes, acid-base, and renal parameters in male cats with urethral obstruction. Journal of Veterinary Emergency and Critical Care, v 13, p. 227-233, 2003.

LEE, J. A.; DROBATZ, K. J. Historical and physical parameters as predictors of severe hyperkalemia in male cats with urethra obstruction. J Vet Emerg Crit Care 2006; 16: 104-111.

NELSON, R. W. \& COUTO,C.G. Medicina Interna de Pequenos Animais. 2.ed.Rio de Janeiro: Guanabara Koogan, 2001.1084p.

MUIR, W. The cardiorespiratory and anesthetic effects of clinical end supraclinical doses of alfaxalone em cats. Veterinary Anaesthesia and Analgesia, v 36, p. 42-54, 2009.

MUIR, WW3RD, GADAWSK JE. Cardiovascular effects of a higher dose of romifidine in propofol-anesthetized cats. American Journal Veterinary Research, v, 63, p. 1241-1246, 2002.

PAWSON, P.; FORSYTH, S. Agentes anestésicos. In: MADDISON, E.J.; PAGE, S.W.; CHURCH, D.B. Farmacologia clínica de pequenos animais. Rio de Janeiro: Elsevier, 2010, p.83112.

PINZON, P. W.; MOREIRA, A. S.; SPEROTTO, A. A.; Avaliação microbiológica do propofol após uso na rotina anestésica. XVII Seminário Internacional de Ensino, Pesquisa e Extensão, UNICRUZ, 2012.

REINEKE, E. L. Feline Urethral Obstruction: Emergency Treatment and Stabilisation. In: Emergency Critical Care UK Annual Congress, 11, 2014, Philadelphia. Anais 11th Emergency Critical Care UK Annual Congress, 2014. Philadelphia: Vets Now, 2014. p 51-57. Disponível em: https://www.vets-now.com/vetprofessionals/training/congress/congress-downloads/. Acesso em 05 fev. 2016.
REISINE T, PASTERNAK G: Opioid analgesics and antagonists, IN HARDMAN JG, LIMBIRD LE, GILMAN AG, ET AL (eds): Goodman \& Gilman's, The Pharmacological Basis of Therapeutics (ed 10). New York, McGraw-Hill, 2011, p. 357-358, 592, 594

RIESER, T. M. Urinary tract emergencies. Veterinary Clinics North America. Small Animal Practice, v. 35, p. 359-373, 2005.

RIESER, T. M. Arterial and Venous Blood Gas Analyses. Topics in companion animal medicine. v. 28, n. 3, p 86-90, 2013. Disponível em: http://www.companimalmed.com/article/S19389736(13)00032-9/fulltext. Acesso em 15 de jul. 2017.

ROBERTSON, S. Anesthesia for Feline Urethral Obstruction. Anesthesic Protocols for Specific Conditions. The Veterinay clinics of North America. Small animal practice. v. 22, n. 2, p. 475478, 1992.

SCHAEFER TJ, WOLFORD RW. Disorders of potassium. Emergency Medicine Clinics of North America. v. 23, n. 3, p. 723-747, 2005. Disponível em: https://www.ncbi.nlm.nih.gov/ pubmed/15982543. Acesso em 09 de dez. 2016.

SLINGERLAND, L. I.; ROBBEN, J. H.; SCHAAFSMA I. Response of cats to familiar and unfamiliar human contact using continuous direct arterial blood pressure measurement. Research in Veterinary Science. v. 85, n. 3, p. 575- 582, 2008. Disponível em: http://www.sciencedirect.com/science/article/pii/ S0034528807003049. Acesso em 08 de dez. 2016.

SOARES, J. A.; LEITE, J. A.; RABELO, R. C. Abordagem otimizado do felino obstruído. In: Rabelo, C. C. Fundamento de terapêutica em medicina veterinária. Rio de Janeiro: L. F. Livros, 2005 , p. $465-470$.

SUDO, R. T.; BONFÁ, L. TRACHEZ, M. M.; DEBON, R.; RIZZI, M. D. R.; SUDO, G. Z. Anesthetic profile of a non-lipid propofol nanoemulsion. Revista Brasileira de Anestesiologia, v. 60, n. 5, p. 475-483, 2010. Disponível em: http://www.sciencedirect.com/ science/article/pii/S0034709410700593. Acesso em 09 dez. 2016.

VICKI, L. Anesthetic Protocols for Common Emergencies. Veterinary Clinics Small Animimals, v. 35, p. 446- 448, 2005.

WARNE, L. N; BETHS, T; WHITTEM, T; CARTER, J. E; BAUQUIER, S.H. A review of the pharmacology and clinical appliocation of Alfaxalone in cats. The Veterinary Journal, v. 203, n.2, p. 141 - 148, 2015. Disponível em: http://www.sciencedirect. com/science/article/pii/S1090023314005073?via\%3Dihub. Acesso em 18 de jul 2017.

WHITTEM, T.; PASLOSKE, K. S.; HEIT, M. C.; RANASINGUE, M. G. The pharmacokinetics and pharmadynamics of alfaxalone in cats after single and multiple intravenous administration of Alfaxan- at clinical and supraclinical doses. Journal Veterinary Phamacology Therapeutics v. 31, n. 6, p. 571-579, 2008. 